\title{
Article \\ Generating the Regular Axis from Irregular Column Grids through Genetic Algorithm
}

\author{
Xi Wang ${ }^{1, *} \mathbb{D}$, Cong $\mathrm{Wu}^{1, *}$ and Chengjun Bai ${ }^{2}$
}

1 School of Architecture, Tianjin University, No. 92 Weijin Road, Nankai District, Tianjin 30072, China

2 School of Civil Engineering, Tianjin University, No. 92 Weijin Road, Nankai District, Tianjin 30072, China; babybcj@sina.com

* Correspondence: wangxi88love@tju.edu.cn (X.W.); wucong@tju.edu.cn (C.W.)

check for updates

Citation: Wang, X.; Wu, C.; Bai, C. Generating the Regular Axis from Irregular Column Grids through Genetic Algorithm. Appl. Sci. 2022, 12, 2109. https://doi.org/10.3390/ app12042109

Academic Editors: Zhihan Lv, Kai Xu and Zhigeng Pan

Received: 29 December 2021

Accepted: 14 February 2022

Published: 17 February 2022

Publisher's Note: MDPI stays neutral with regard to jurisdictional claims in published maps and institutional affiliations.

Copyright: () 2022 by the authors Licensee MDPI, Basel, Switzerland. This article is an open access article distributed under the terms and conditions of the Creative Commons Attribution (CC BY) license (https:// creativecommons.org/licenses/by/ $4.0 /)$.
Featured Application: This study proposes an auto-generation method of the regular axis, applied in digital documentation of cultural heritage. The procedure is repeatable, the results show the displacement of columns with visual expression and numerical analysis.

\begin{abstract}
Historic building information modeling (HBIM) provides an index frame for digital documentation of the cultural heritage, as a continuous process of reverse engineering. The index frame should be a regular model, with a clear comprehension of each component; consequently, associated knowledge could be live-updated with the investigation progress. Therefore, the method of data registration stresses its importance. The axis is fundamental for Chinese traditional architecture as the basis for positioning all components in wooden structures. However, displacement often happens. To correct the displacement while modeling, the hypothetical axis should be determined first. This paper thus proposes a method of generating the regular axis from irregular column grids and aims to develop an automatic solution that is repeatable and transplantable. The finite element modeling (FEM) abstracts the actual problem to enable numerical calculation. Starting from a candidate solution, the genetic algorithm calculates a solution closest to the expectation from the possible solutions in several minutes. The standard deviation is used to measure the amount of displacement based on the hypothetical axis, which is expected to be minimum. This method is compatible with most kinds of input data, e.g., point cloud, excel data, 2D drawing, mesh model, etc., and applied to a World Heritage Site in Qufu (Shandong, China). The results show the displacement of columns with visual expression and numerical analysis and prove that the proposed method is repeatable and traceable and can easily be applied to different projects by changing input parameters.
\end{abstract}

Keywords: HBIM; reverse engineering; grid system; column displacement; regularized rebuild; FEM; algorithm generation; heritage documentation

\section{Introduction}

\subsection{Review of Related Works}

During the digital documentation of cultural heritage, displacements are usually found in wooden structures [1-4], resulting in difficulty of positioning while modeling.

Different from modern architecture, in Chinese traditional architecture, the axis is designed for locating column heads, rather than column feet. Because eave columns are inclined and raised in an arithmetic sequence, from center to corner, the plane projection of centroids connection line of eave column heads is rectangular, while the eave column feet are not.

This manufacturing method is documented in "Ying Zao Fa Shi" [5-9] (which states building regulations of Song Dynasty, A.D. 1103), and it can be seen in many heritage sites in East Asia nowadays. However, this method is difficult to verify, as all the wooden structures have lost their original positions. 
As a continuous process of reverse engineering, i.e., regularized rebuild or ideal reconstruction [10-13], an HBIM model should be an index frame [14,15], a prototype library [16-18], or an ideal model [19-21], of which components could be comprehended with architectural semantics, and knowledge could be associated through multidisciplinary collaboration. The traditional method of digital documentation in China accumulates a large number of 2D drawings, yet mistakes occur while modeling with reference to these data.

As a result, the data acquired from 2D drawings have to be registered, e.g., a hypothetical orthogonal grid system. Each axis is calculated through a certain algorithm so that the average distance between each "as-found" column centroid and "as-designed" column centroid is expected to be the smallest. Once an ideal grid system is established, the numerical analysis could be applied.

In recent years, the method of algorithm modeling (or generative modeling) with visual programming tools is developing increasingly [22-31]. This technique provides traceable solutions which document the whole modeling procedure, including input parameters, process algorithms, and resulting models. Based on this foundation, the research that considers grids as a whole of the interrelated system cloud be further developed.

To create a whole column grid system, finite element modeling (FEM) with the utilization of genetic algorithm is chosen as the method, as the multi-goals (result axes) are known quantities while the genomes (input parameters) are unknown quantities. The FEM transforms the problem of infinite degrees of freedom in a continuous domain into the problem of finite degrees of freedom in a discrete domain, enabling numerical calculation [32-36]. Furthermore, compiling algorithms for mathematical representation, the genetic algorithm is available to implement for optimizing FEM, with a Grasshopper plug-in, the Galapagos generic solvers [37]. The Rhinoceros thus is chosen as the software platform for the automatic solution through the genetic algorithm with FEM. The Galapagos as an evolutionary solver in Grasshopper has been widely used for parametric design and result optimization [38-46].

\subsection{Purpose and Significance}

This paper aims to propose a method of automatically generating whole axes in column grids at the same time with visible algorithm nodes and thousands of iterations, which would be less possible by manual operating.

Starting with a pre-given candidate solution and point cloud, the Galapagos module tries to move and rotate all of the axes with the expectation that the average distance between each ideal axis intersection point and as-found column head centroid is the smallest. When applying to different kinds of heritage sites, one only needs to change input parameters by adjusting the numeric slider or removing non-participate columns, etc., and then the procedure would finish the calculation within less than an hour.

The proposed method consists of several steps, as shown in the flowchart (Figure 1). 


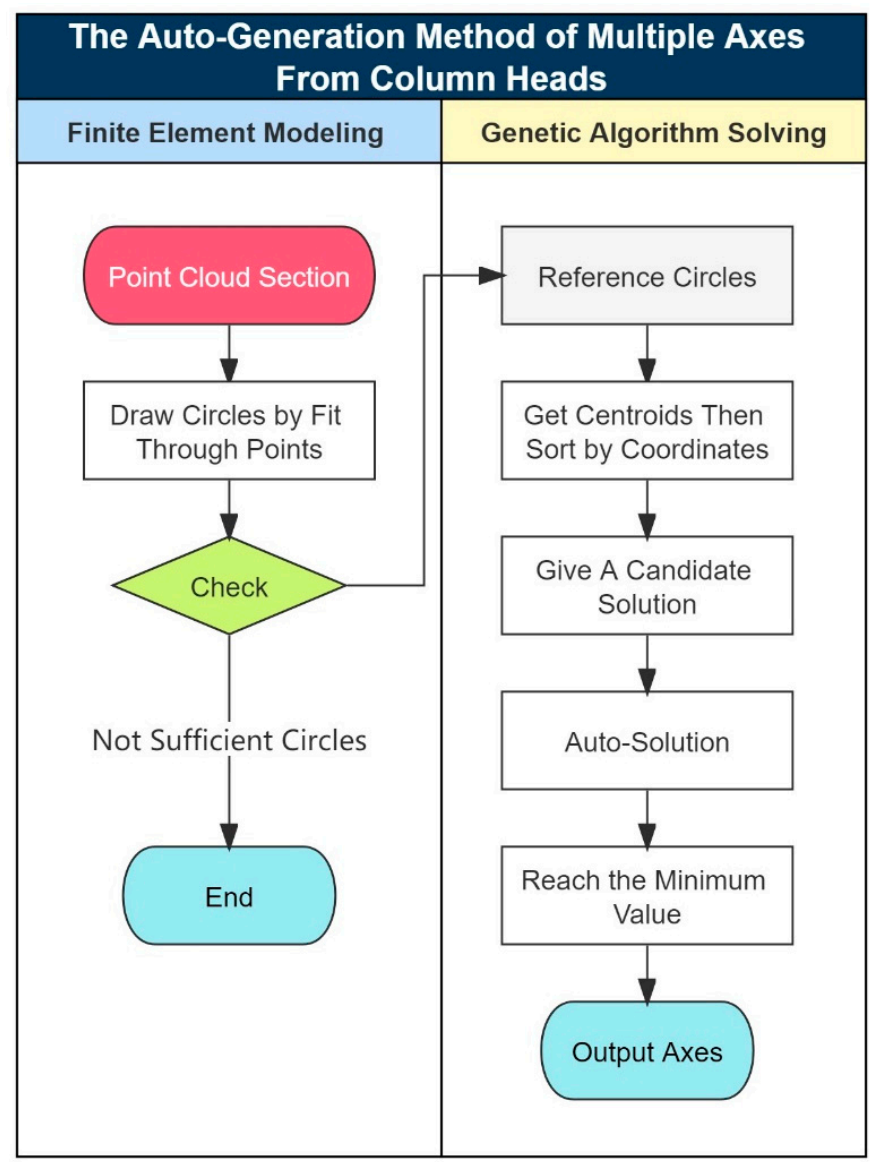

Figure 1. The Auto-generation method.

\section{Materials and Methods}

\subsection{Finite Element Modeling Using Genetic Algorithm}

Take the Kuiwen Pavilion as an example. It is located in the Temple of Confucius, which has been part of the UNESCO World Heritage Site "Temple and Cemetery of Confucius and the Kong Family Mansion in Qufu" since 1994. The Kuiwen Pavilion was built in the Imperial style, which means that the structural members should ideally form column grids with rectangle spaces.

However, based on a plane section of column heads from the point cloud, an irregular grid system shows as-found column heads together with beams (Figure 2).

Column heads serve as joints of beams, and together with beams, they form a spatial framework, therefore it can be assumed that displacements are evenly distributed from their original place, i.e., they meet Laplace-Gaussian distribution. To bring this problem to numerical calculation, the column head could be simplified to one circle, which could be deconstructed into two parameters: diameter and a centroid (point).

To define an axis, at least two centroids are required, yet this axis is certainly determined by axiom. However, if there are three points or more, an axis is uncertainly determined by least-squares fitting. Consequently, it can be assumed that grids are rectangles, displacements of column heads are evenly distributed along each rebuild axis, and the variance of distances between current centroids and rebuild centroids of column heads has a minimum value. Therefore, Gauss sum instead of variance is expected to be minimum; thus, it is used as the goal.

$$
\sigma=\sqrt{\operatorname{Var}(X)}=\sqrt{E\left[(X-\mu)^{2}\right]}
$$




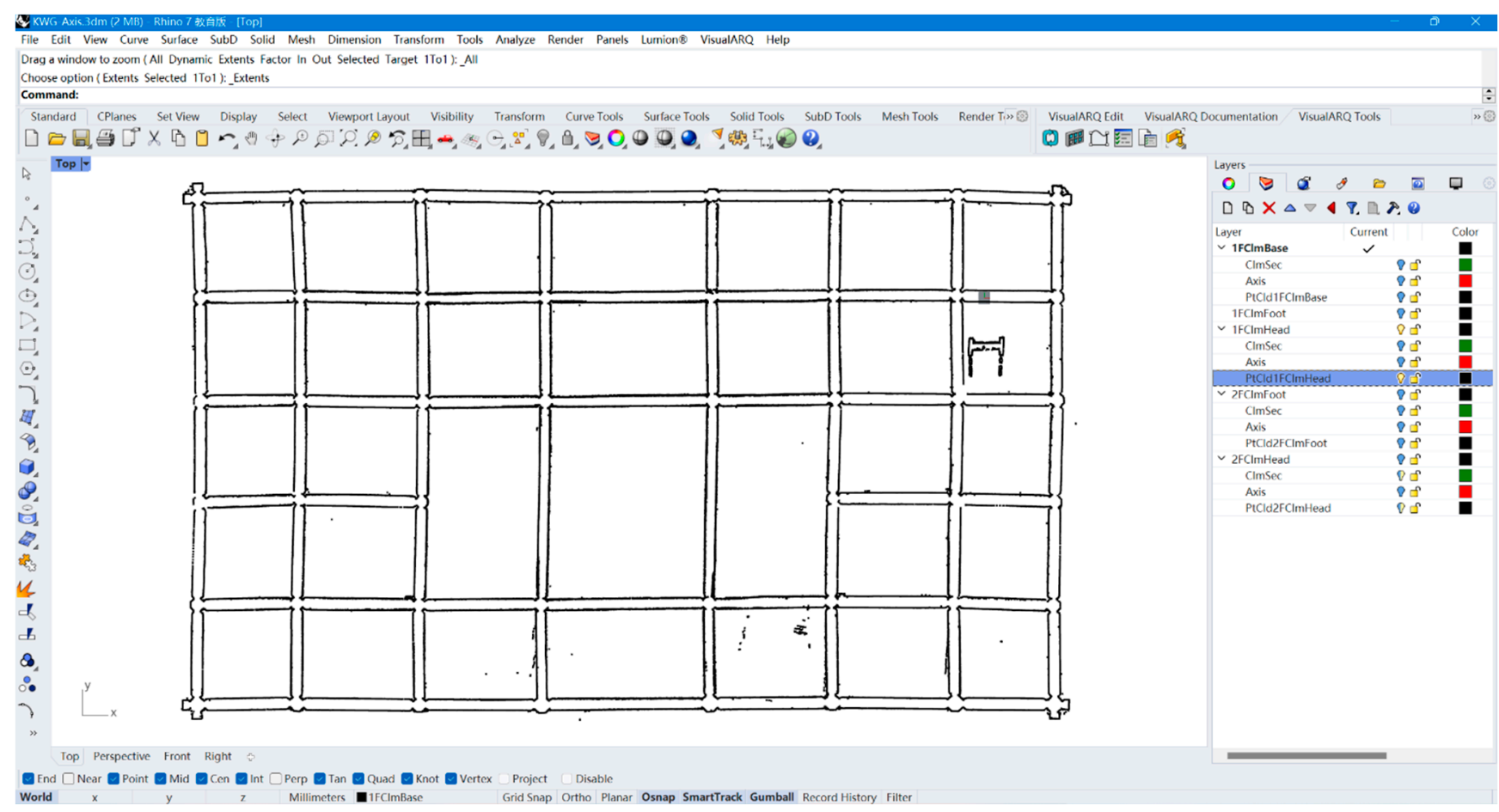

Figure 2. A plane section of column heads from the point cloud shows an irregular grid system.

The variance of a random variable $X$ is the expected value of the squared deviation from the mean of $X$. That is, variance equals the average value of the Gauss sum. The squared root of the variance is the standard deviation, which is used as an evaluating indicator of the result.

Therefore, the problem is simplified as such: how can one generate all axes at the same time while the minimum value of Gauss sum is reached?

The methodology is shown as follows:

1. Use the Circle-FitPoints command to manually select related points from the point cloud of a column head and then automatically draw a circle of the section profile. Repeat to go through all column heads (Figure 3).

2. Launch Grasshopper, use the Curve component to collect all circles, use Project to obtain circles in the $X$-plane, use Area to obtain centroids of circles, use Deconstruct to obtain $\mathrm{X}, \mathrm{Y}$, and $\mathrm{Z}$ values, and use Sort List to sort centroids in a certain order (Figure 4).

3. Use Number Slider to manually give a range for initial parameters including motions and rotations of axes, then connect them to the Genome of Galapagos as a candidate solution for the genetic algorithm (Figure 5).

4. At this moment, a candidate solution and resulting axes are shown; the average distance is $144 \mathrm{~mm}$ (Figure 6).

5. This solution could be optimized as long as a goal is given to the fitness of Galapagos, therefore Gauss sum is applied to calculate the applicability of axes, then the average distance between current centroids and rebuild centroids is applied to evaluate the result (Figure 7).

6. Open the Galapagos, start the solver, and during the process, the result is displayed in real-time (Figure 8).

7. When the result seems stable after 5 min of calculation, it could be output as the final solution, if the average distance is acceptable. Or wait until the minimum value is reached, though it may take longer (almost $1 \mathrm{~h}$ ). The average distance is $68 \mathrm{~mm}$ (Figure 9). 


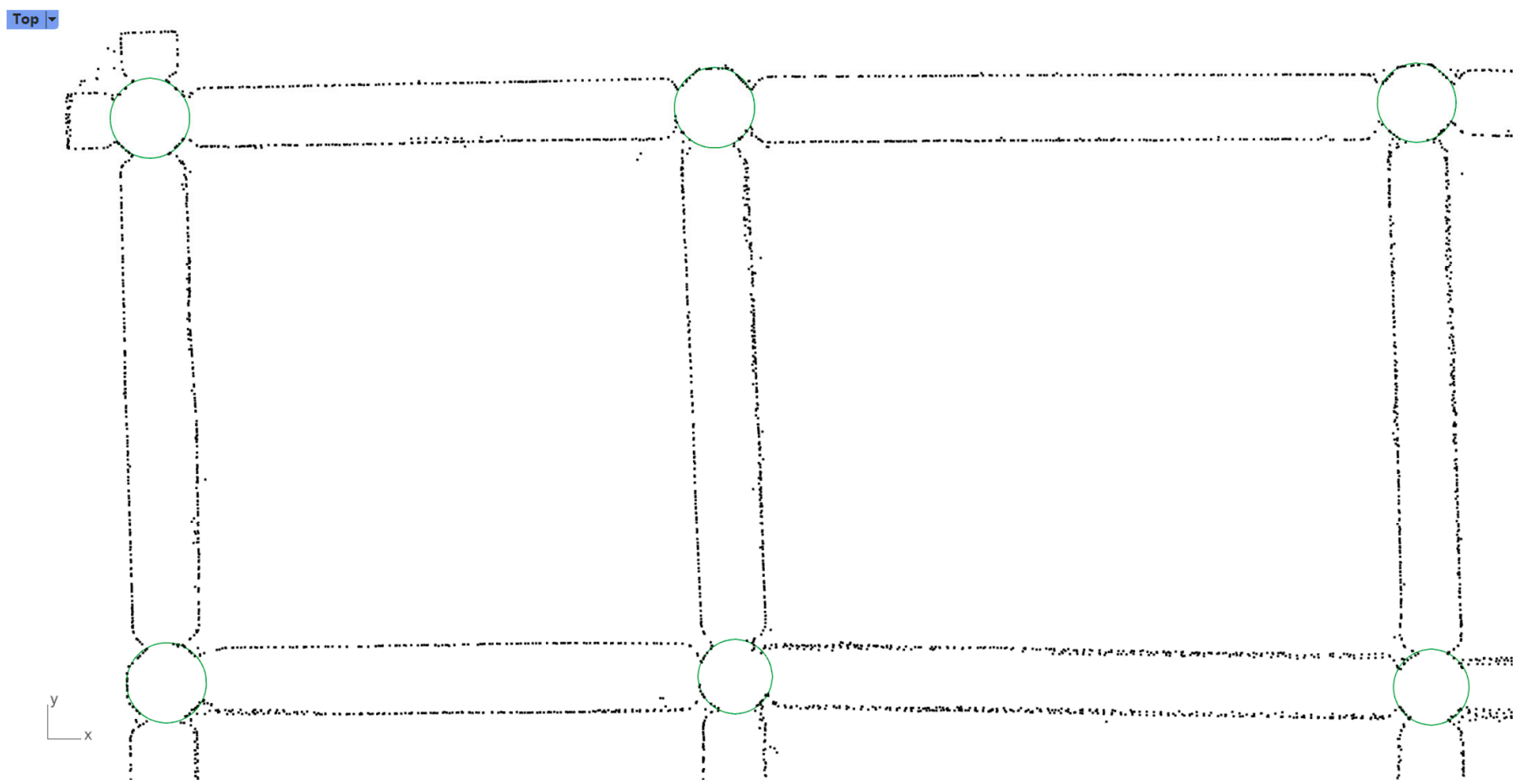

Figure 3. Circles are generated from select points (partial display).

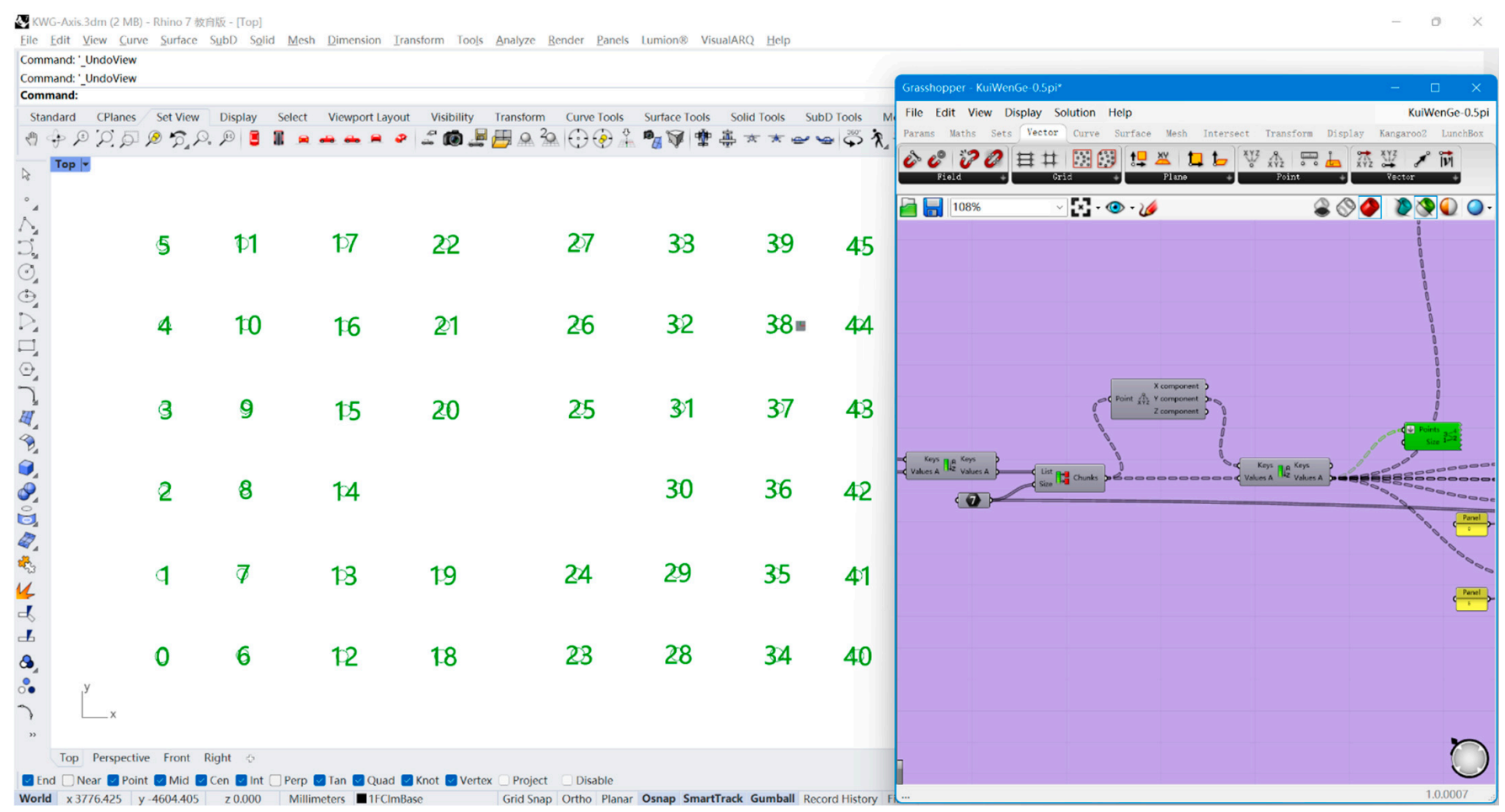

Figure 4. Sort centroids by coordinates.

As is shown in Figure 9, displacements of column heads including vectors (arrows) and lengths (numbers) are calculated, while all of the axes are generated. The solution process takes $\mathbf{3} \mathbf{~ h ~} \mathbf{1 6} \mathrm{min}$ and stops automatically after reaching the minimum value.

This result shows that the manually rotated point cloud is very close to the orthogonal direction as the initial angle is 0.00002 degrees. The winding corridor has an average width of $3493 \mathrm{~mm}$, and the four dimensions (3485 mm, $3488 \mathrm{~mm}, 3498 \mathrm{~mm}, 3500 \mathrm{~mm}$ ) have a standard deviation of $6 \mathrm{~mm}$. Therefore, the winding corridor could be regarded as 
equidistantly offset from the second circle of columns. Similarly, the whole grid system could be regarded as symmetric.

The components of the entire node-visible algorithm are shown in Figure 10.

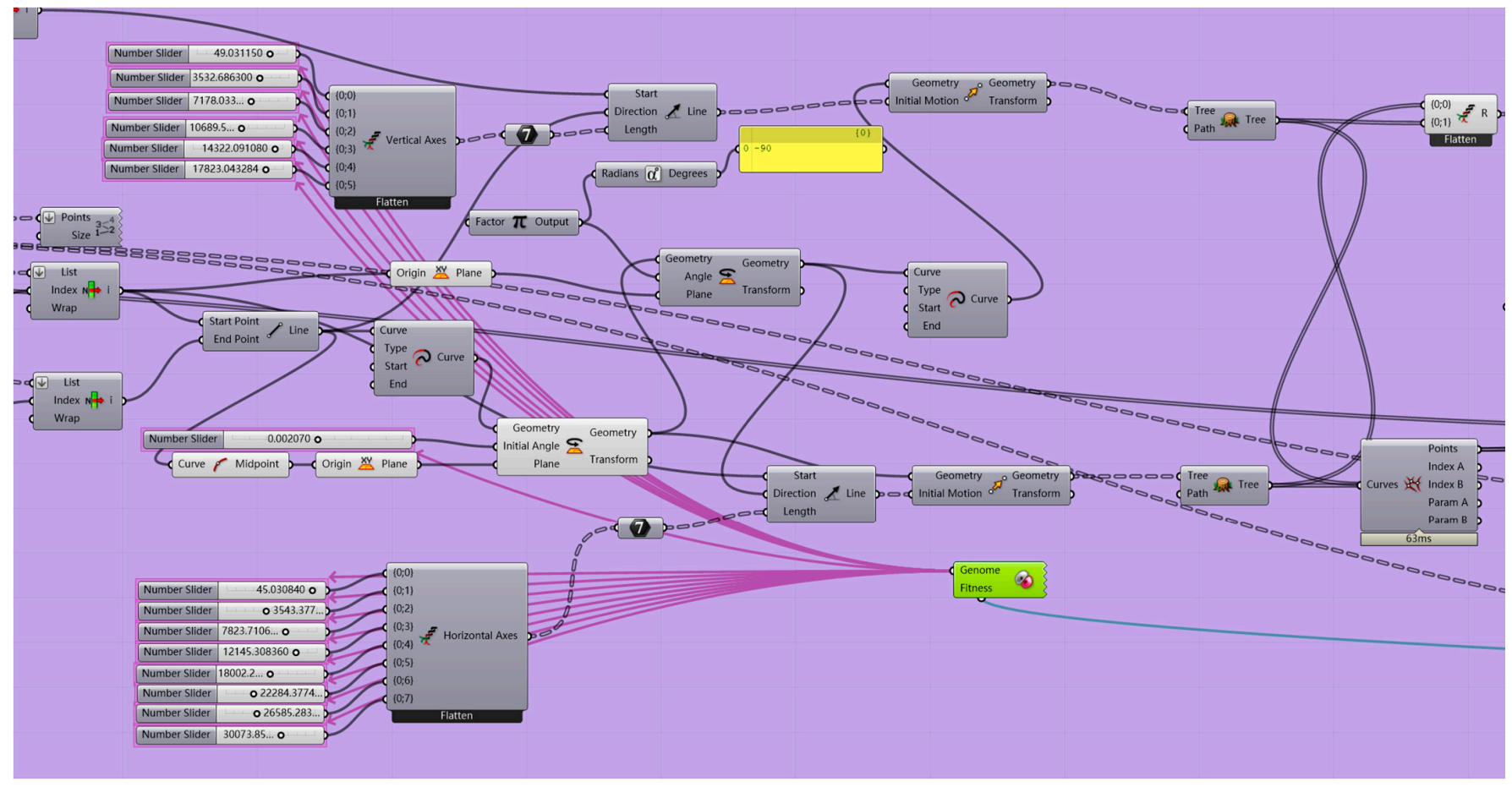

Figure 5. Use Number Slider to give a candidate solution to the Genome (red wires) of Galapagos for genetic algorithm solution.

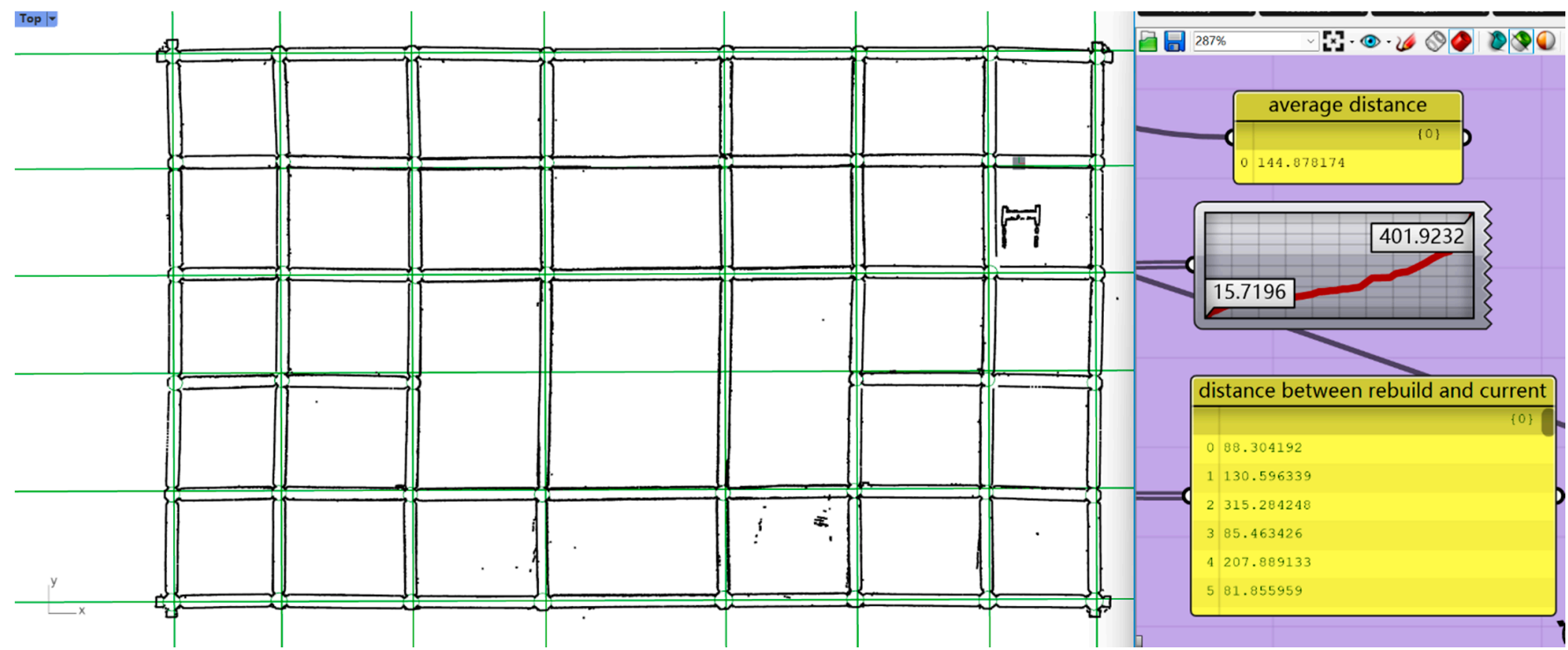

Figure 6. A candidate solution of generating axes and numerical analysis of this moment.

\subsection{Hypothesis and Verification}

Ideally, if two tangent circles of $400 \mathrm{~mm}$ diameter arrayed in a vertical line are given, one axis should be generated; at this moment, each distance should be zero, the angle of the axis should be zero, and the aligned dimension between two horizontal axes should be also $400 \mathrm{~mm}$. After the solution process, the result successfully verifies the hypothesis, although it takes 33 min to reach the goal (Figure 11). 


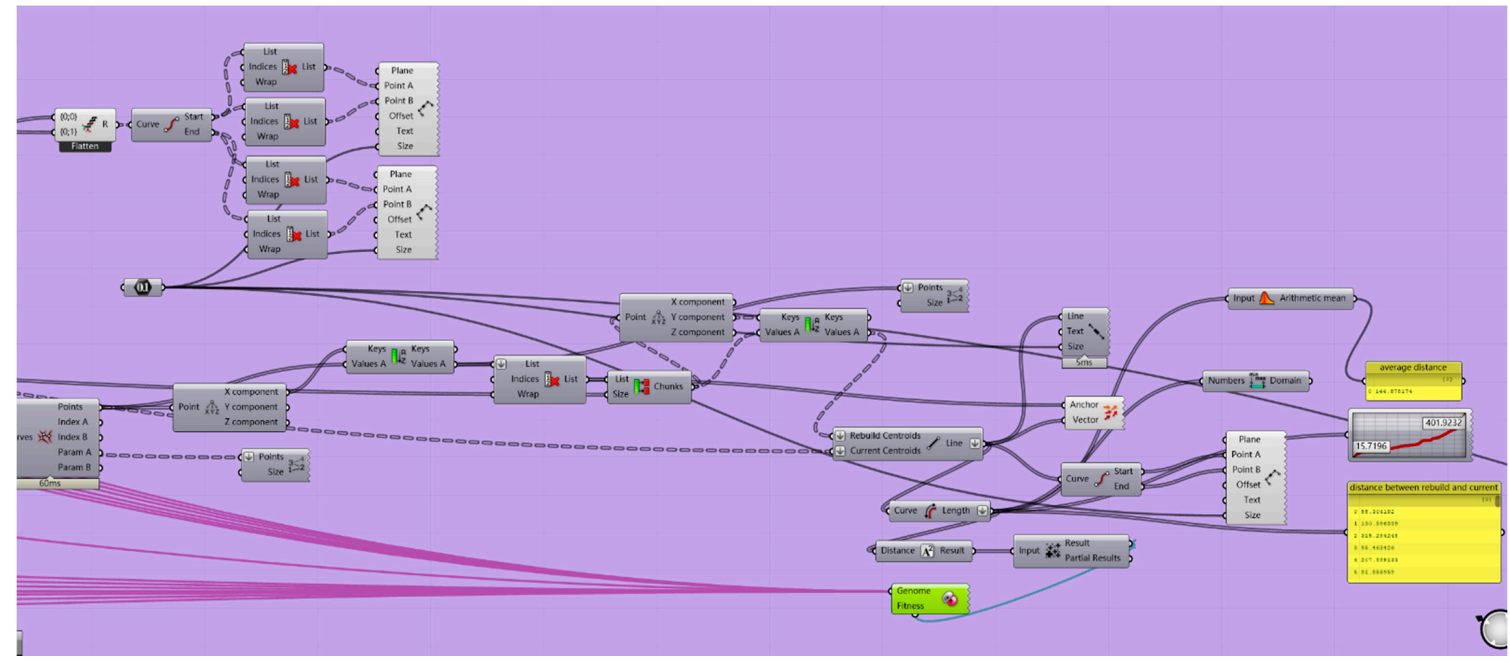

Figure 7. Connect Gauss sum to fitness (blue wire) for genetic algorithm solution.
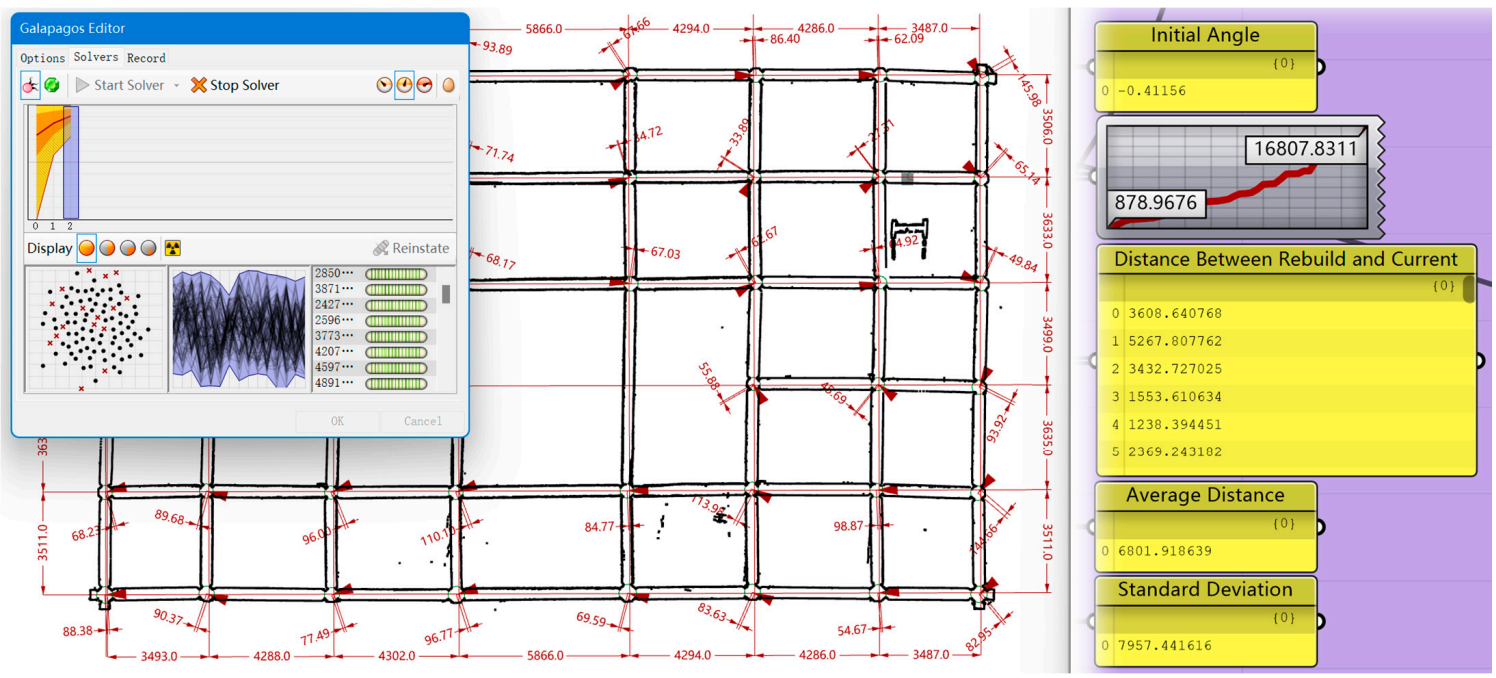

Figure 8. The beginning of the solution process and numerical analysis of this moment.

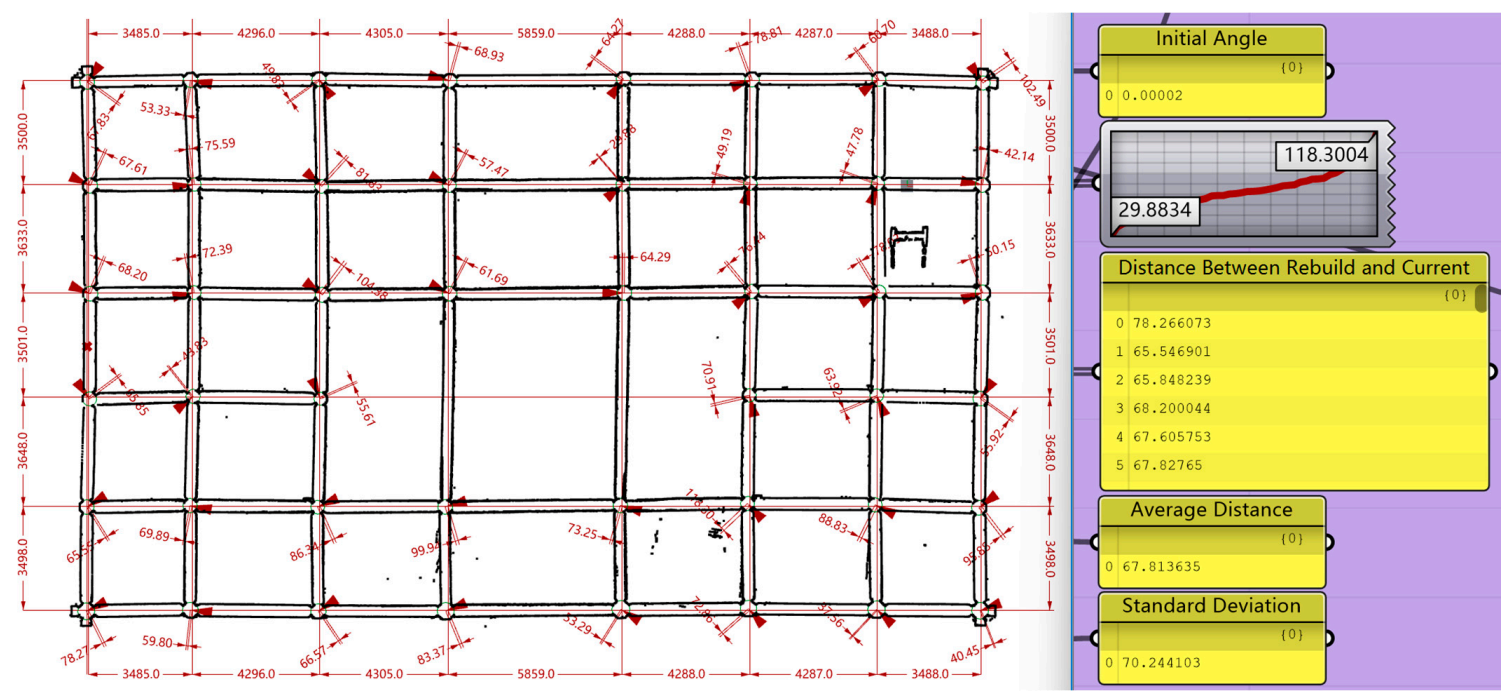

Figure 9. The result of the solution process and numerical analysis of this moment. 


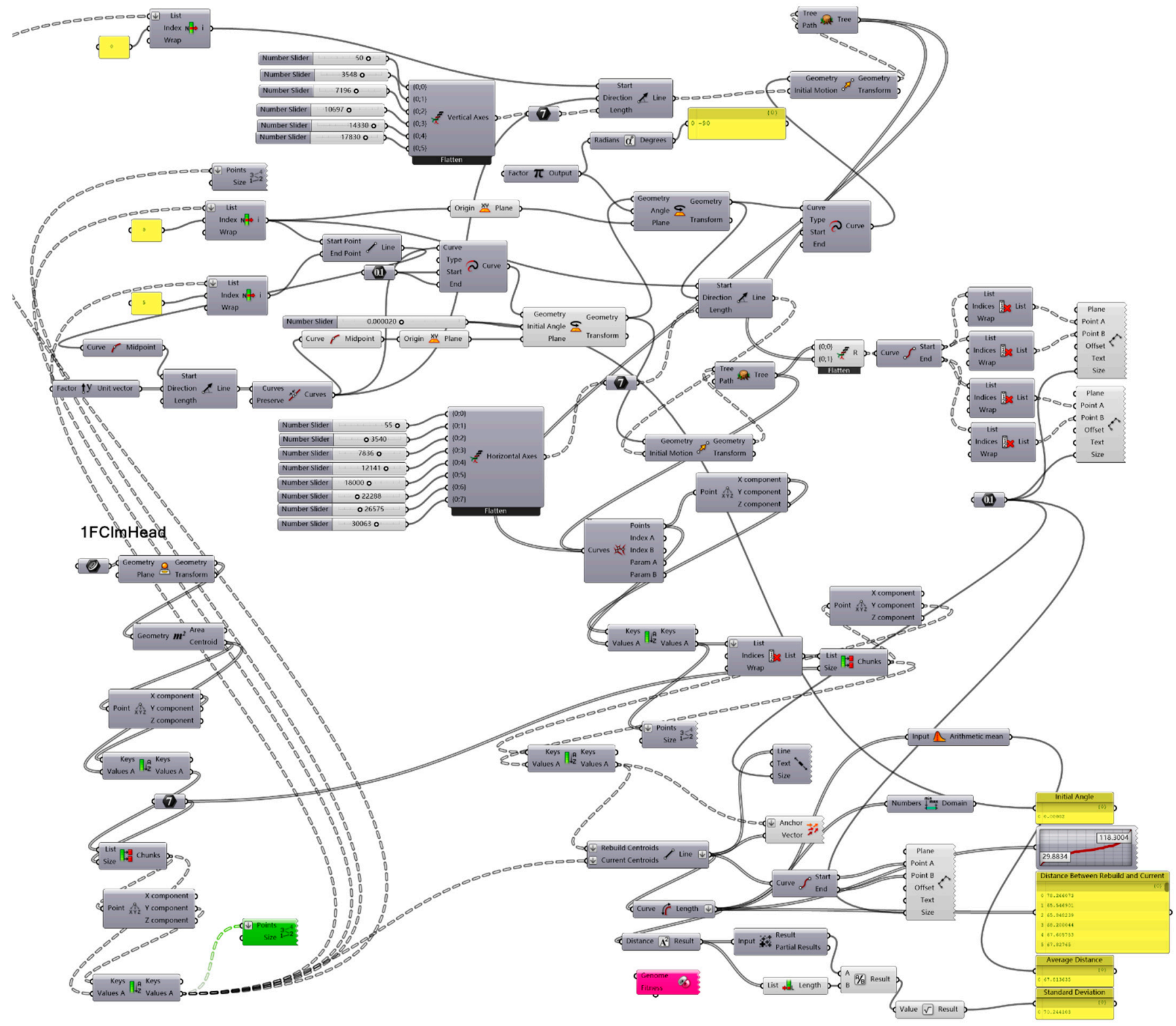

Figure 10. The Grasshopper components of finite element modeling and genetic algorithm.

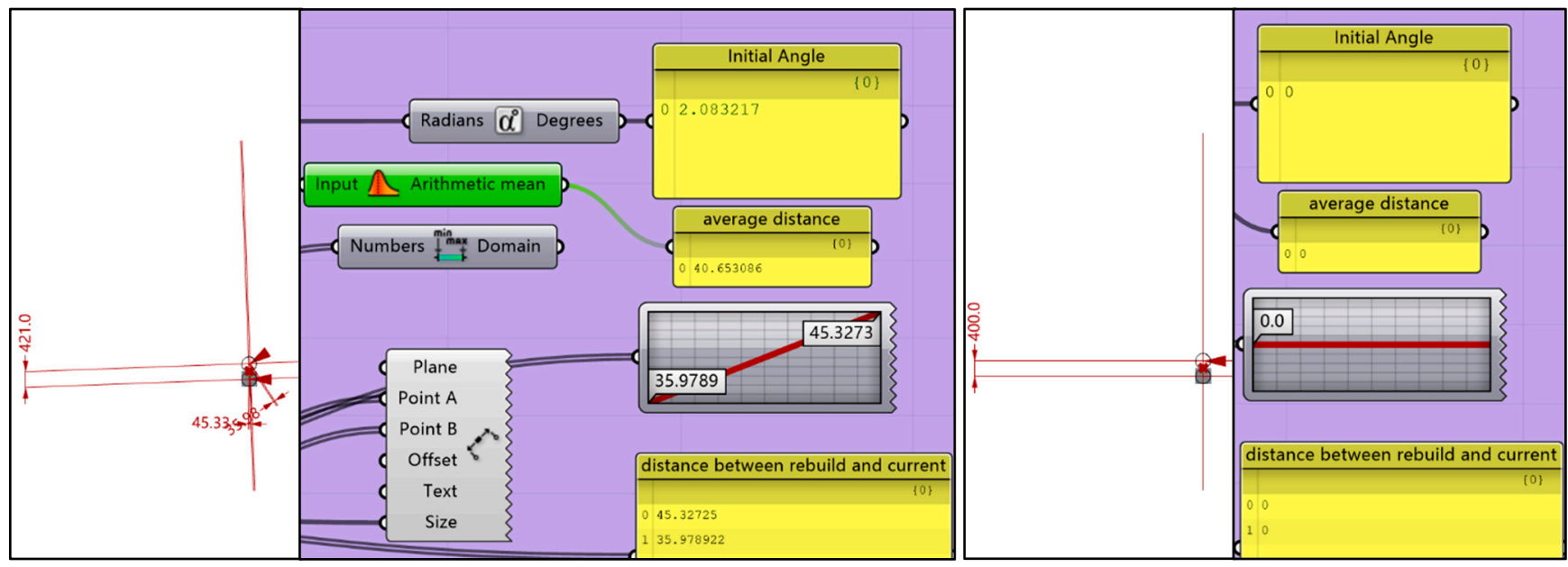

Figure 11. Verification of two columns (the disordered axes on the left, the result axes on the right). 
If there are four circles, equally distributed along the vertical axis, the result should restore the movement and rotation, and the average distance should be $200 \mathrm{~mm}$. However, the result shows a wrong solution (Figure 12). The average distance is $182 \mathrm{~mm}$, and the initial angle is not zero. This is because four circles could form a rhombus, for which it is impossible to determine the only axis.
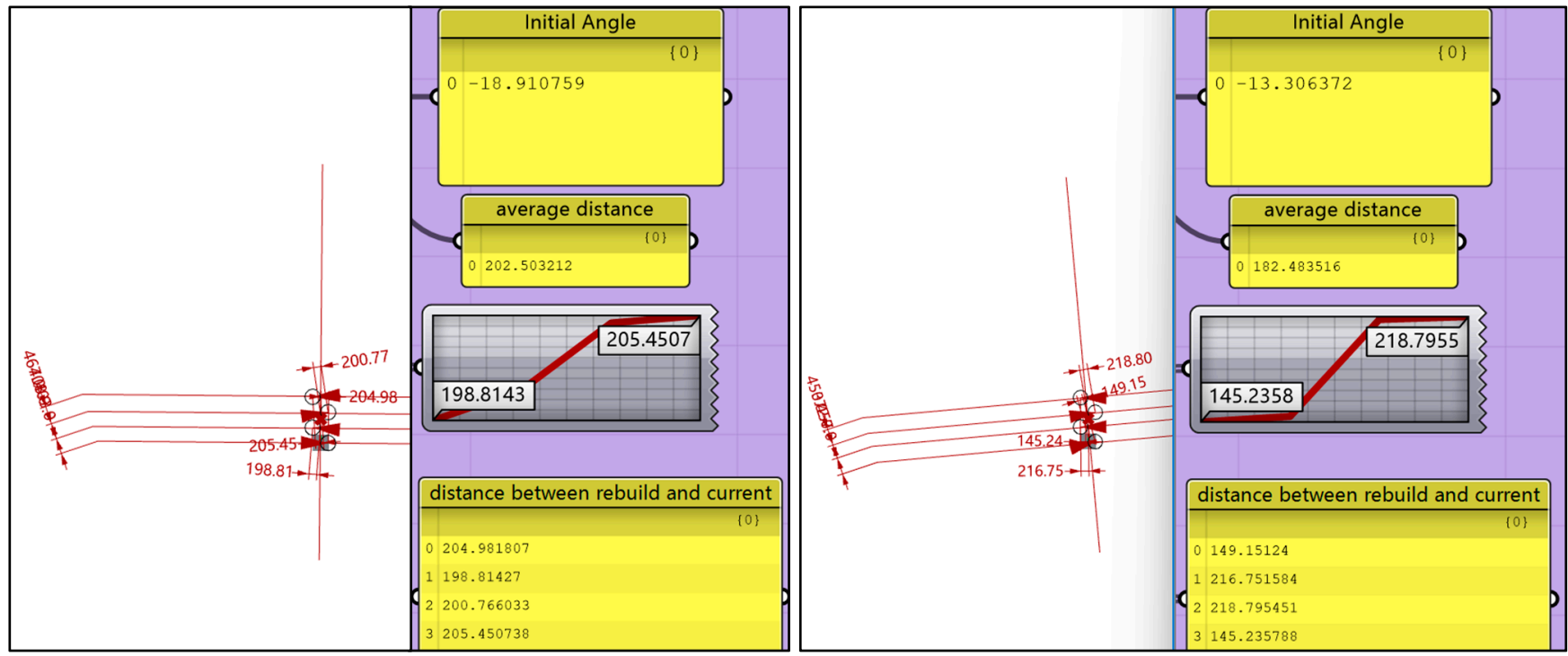

Figure 12. Verification of four columns (the disordered axes on the left, the result axes on the right).

Therefore, the hypothesis is changed to eight circles, to form a symmetric grid system in which the horizontal dimension is $1600 \mathrm{~mm}$ and each vertical dimension is $800 \mathrm{~mm}$, then these circles are distributed equally $(200 \mathrm{~mm})$ along each vertical axis.

The generated axes successfully restore the movement and rotation (Figure 13), although the solution process takes $\mathbf{5 4} \mathbf{m i n}$ to reach the minimum value then stops automatically. However, when this grid system is asymmetric, the resulting axes have a smaller average distance $(183 \mathrm{~mm})$ than the initial pre-given axes $(200 \mathrm{~mm})$ and a smaller standard deviation $(188 \mathrm{~mm})$ than the initial pre-given axes $(200 \mathrm{~mm})$, but they fail to restore the original grids (Figure 14).
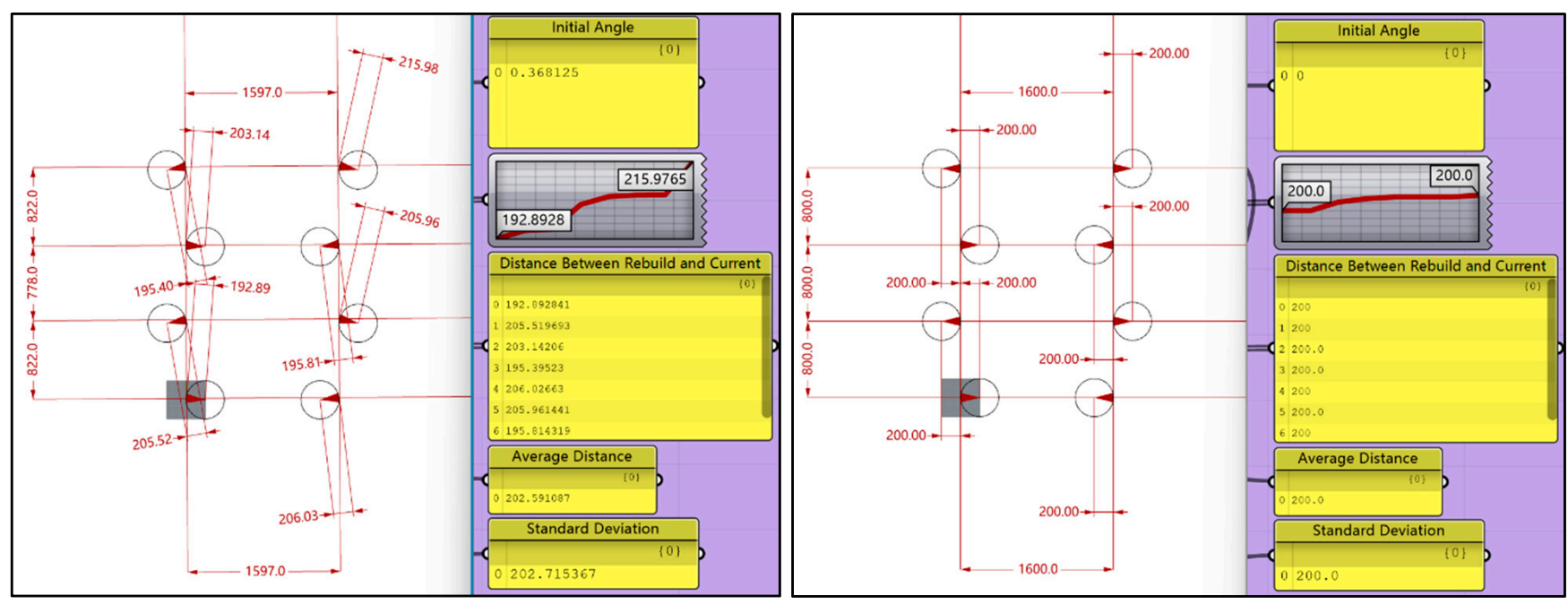

Figure 13. Verification of eight symmetric columns (the disordered axes on the left, the result axes on the right). 


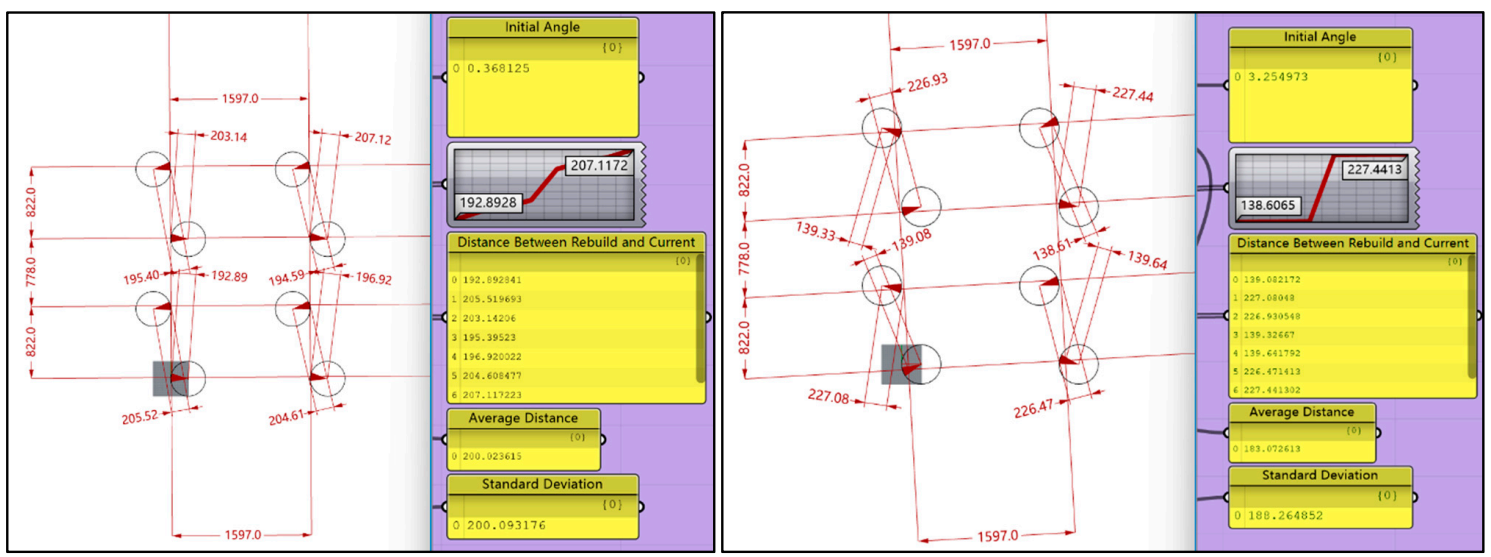

Figure 14. Verification of eight asymmetric columns (the disordered axes on the left, the result axes on the right).

Furthermore, both asymmetric and symmetric grid systems of six circles are tested. The only difference is that the top two circles are removed. Both resulting axes have a smaller average distance $(177 \mathrm{~mm})$ than the initial pre-given axes $(290 \mathrm{~mm}$ and $202 \mathrm{~mm})$, and both resulting axes have a smaller standard deviation $(188 \mathrm{~mm})$ than the initial pregiven axes (312 $\mathrm{mm}$ and $203 \mathrm{~mm}$ ). The solver has reached the minimum value and stopped automatically (Figures 15 and 16).
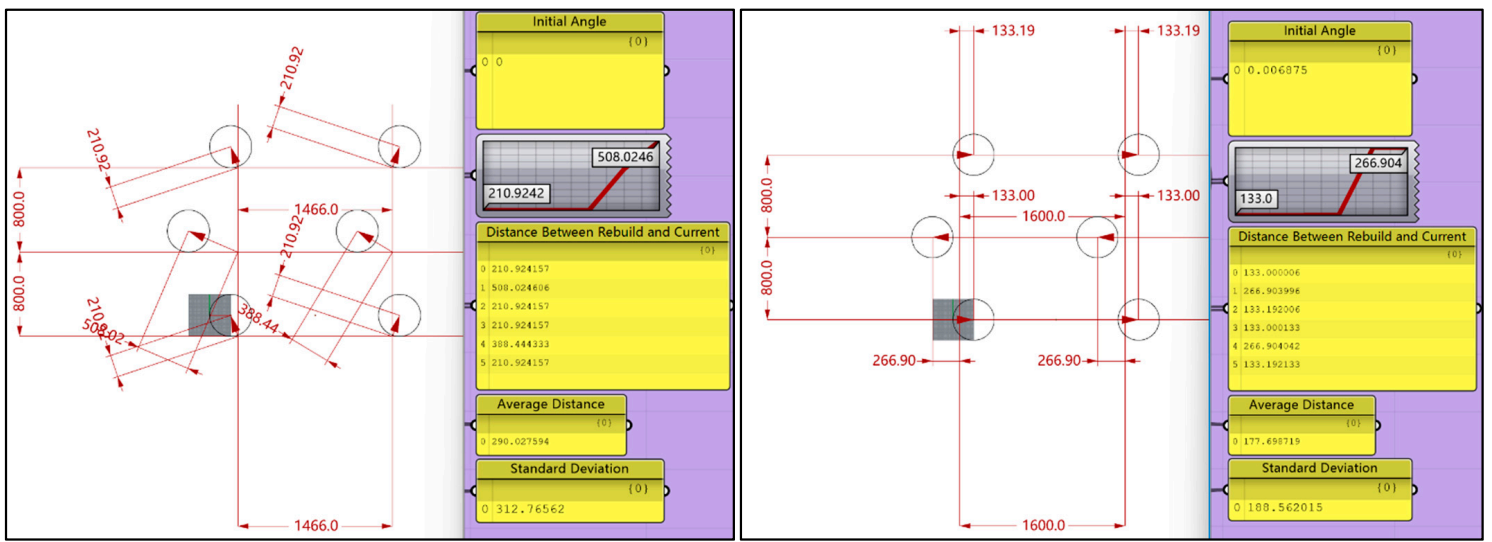

Figure 15. Verification of six asymmetric columns (the disordered axes on the left, the result axes on the right).

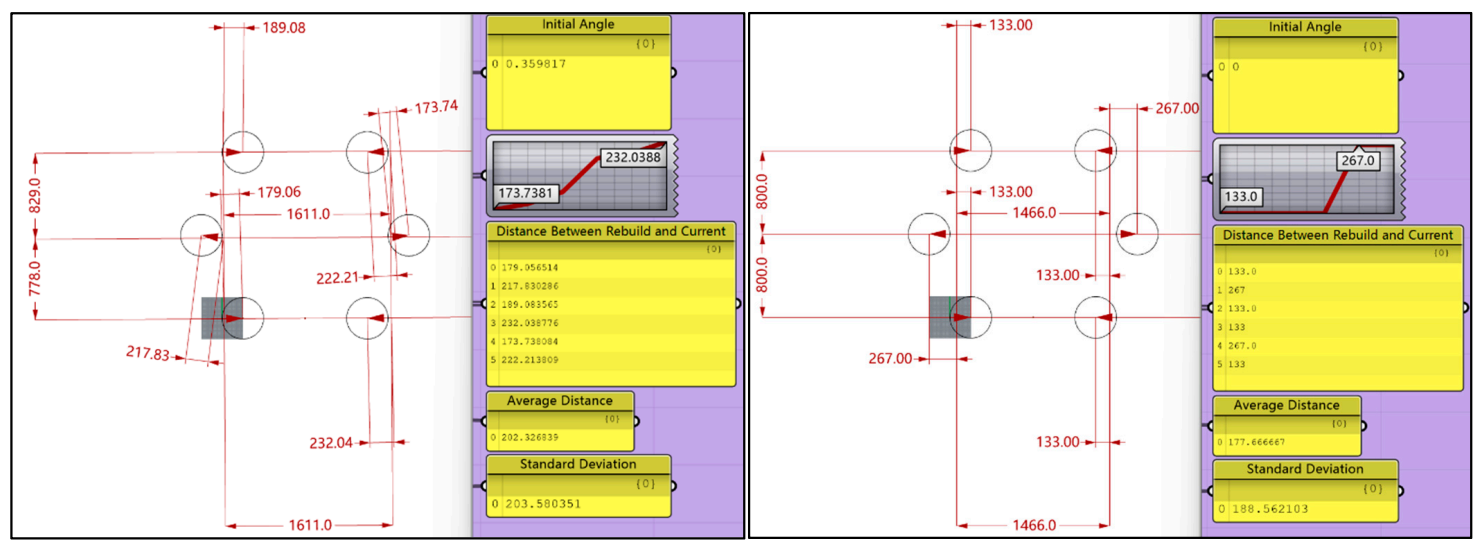

Figure 16. Verification of six symmetric columns (the disordered axes on the left, the result axes on the right). 
Additionally, to verify that an odd number of columns would have an inaccurate result, the hypothesis is changed to 10 circles. The generated axes successfully restore the rotation but fail to restore the movement. The solver has reached the minimum value and stopped automatically (Figures 17 and 18).
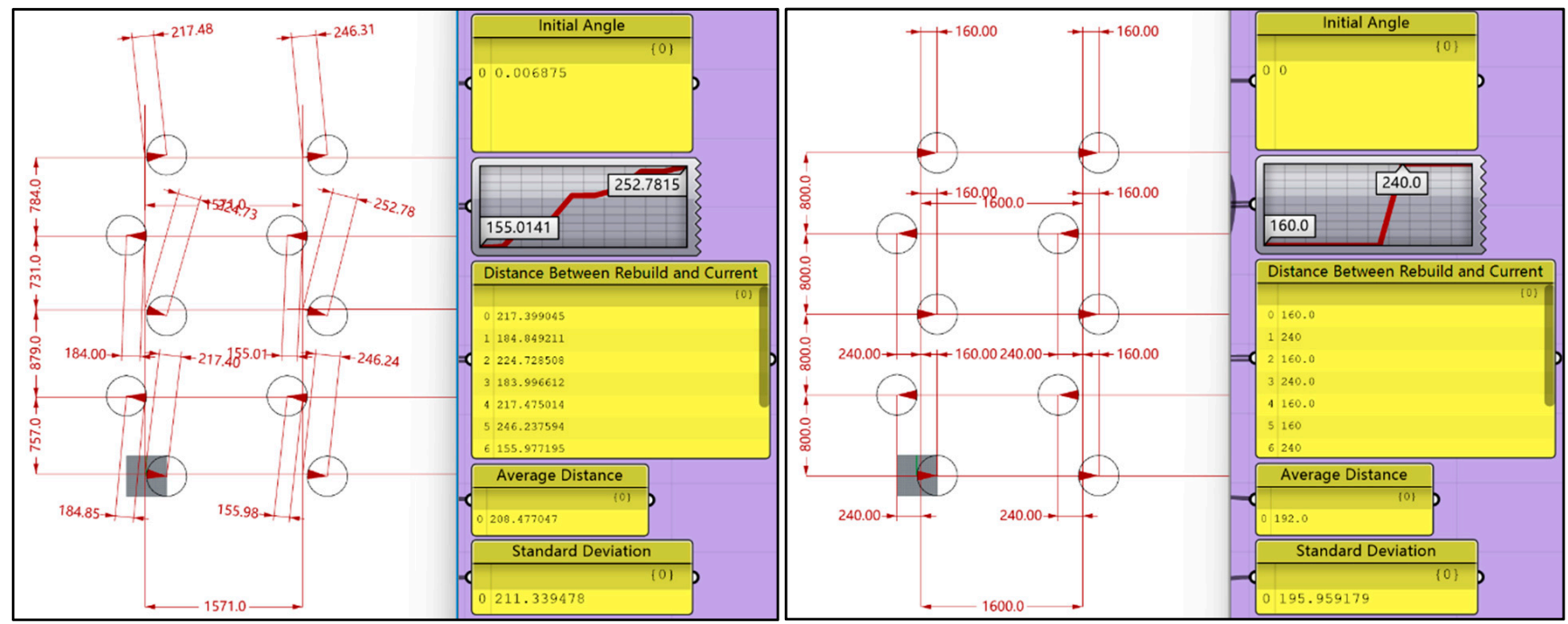

Figure 17. Verification of 10 asymmetric columns (the disordered axes on the left, the result axes on the right).
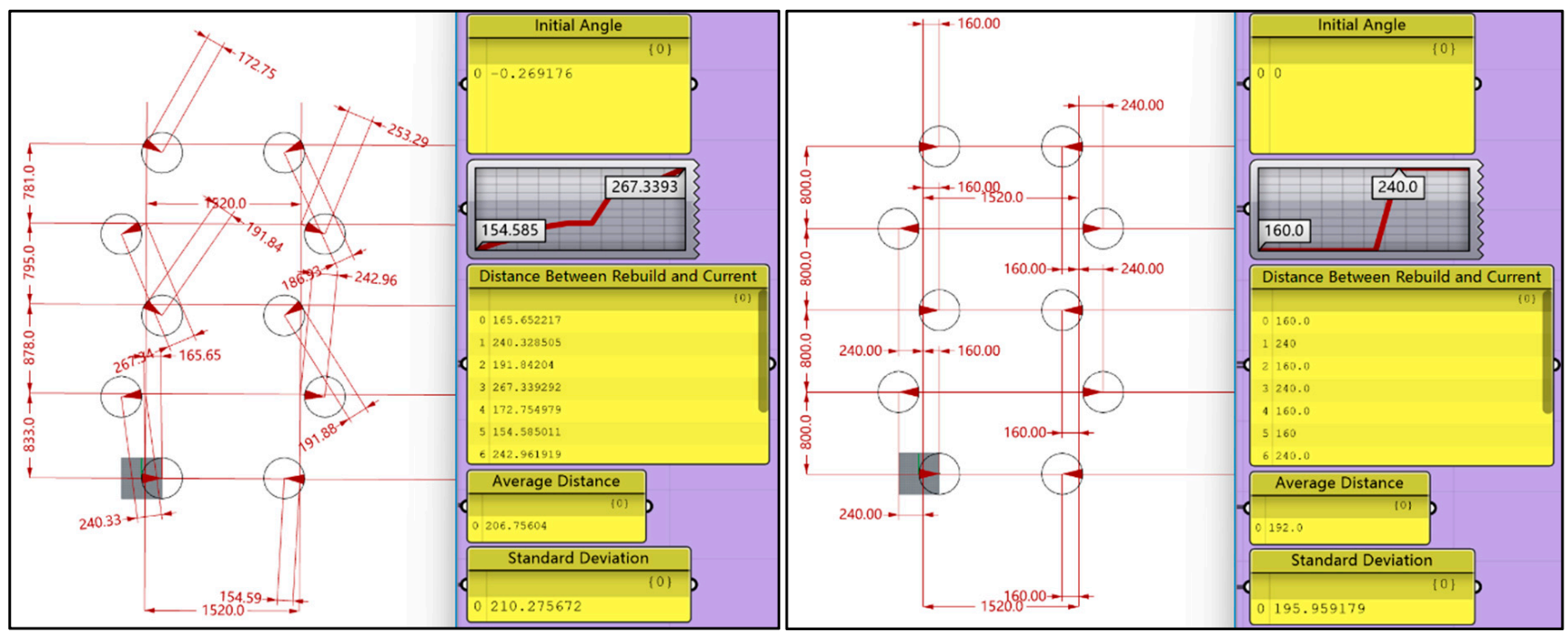

Figure 18. Verification of 10 symmetric columns (the disordered axes on the left, the result axes on the right).

This result shows that for linear-arrayed circles of a vertical axis, each column shares equal weight, so the three circles have more "attraction" than two circles, and the axis deviates to their side. The average distance is $192 \mathrm{~mm}$, which is even more "ideal" than the original distribution of $200 \mathrm{~mm}$, despite the axis not being the same as the original one. The standard deviation is $196 \mathrm{~mm}$, which is closer to $200 \mathrm{~mm}$, compared to $188 \mathrm{~mm}$, of six columns. After the solution process is complete, the resulting axes of 10 columns are more accurate than six columns. 


\section{Results}

The results of the hypothesis and verification are concluded in Table 1.

Table 1. The statistics of pre-given axes and generated axes.

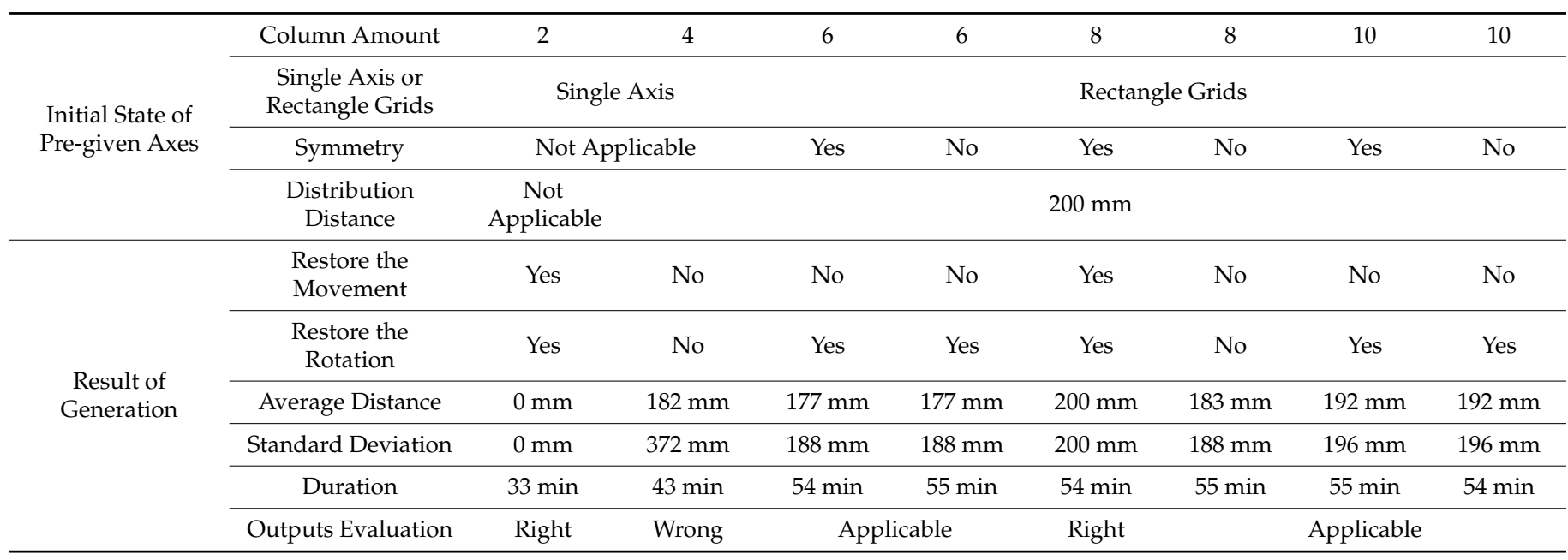

This method is proposed for the correction of an irregular grid system; the result could accurately restore the original axes under certain conditions.

1. At least two rows.

2. Each row has four symmetrically displaced columns or has more than four symmetrically displaced columns as long as the number is even $(6,8,10$, etc.).

Otherwise, the result could not accurately restore the original axes, but is still close to the original axis and still has potential possibilities for application, as it is repeatable and more convenient than manual calculation. The more columns a grid system has, the more accurate the result is.

\section{Conclusions}

This method could either output geometric models or numeric data. After the solution process, the resulting axes could be directly used for modeling. Alternatively, in a collaborative workflow including many sessions, to make data exchange convenient, only grid spacing and rotation angle are required. Both of them are numbers, and therefore easy to store in a general format such as .txt, .xlsx, etc. The grid spacing is used to create a grid system in BIM software such as Autodesk Revit and Bentley Openbuildings Designer. The rotation angle is used to rotate the point cloud to fit the grid system; thereafter, the point cloud is used as a reference during the modeling process.

Although this method aims to automate the solution process, regarding the diversity of architectures there are still manual operations. For example, removing some columns based on the standard column grids is a common practice, such as Kuiwen Pavilion. Not all axis intersections have columns; therefore, the corresponding column has to be removed from the algorithm.

Furthermore, this method could be applied to test whether these columns are designed to be inclined or not. First, the axes of column bases are generated. The centroid of rebuild axes on column bases could be recorded as $\mathrm{C} 0$, and the centroid of rebuild axes on column heads could be recorded as $\mathrm{C} 1$. The vector from $\mathrm{C} 0$ to $\mathrm{C} 1$ on the $\mathrm{XY}$ plane would indicate the movement between the column heads grid system and the column bases grid system. If the column heads grid system is moved to make the $\mathrm{X}$ and $\mathrm{Y}$ coordinates of $\mathrm{C} 1$ and $\mathrm{C} 0$ consistent, the result would indicate whether these columns are designed to be inclined or not (Figures 19 and 20). 


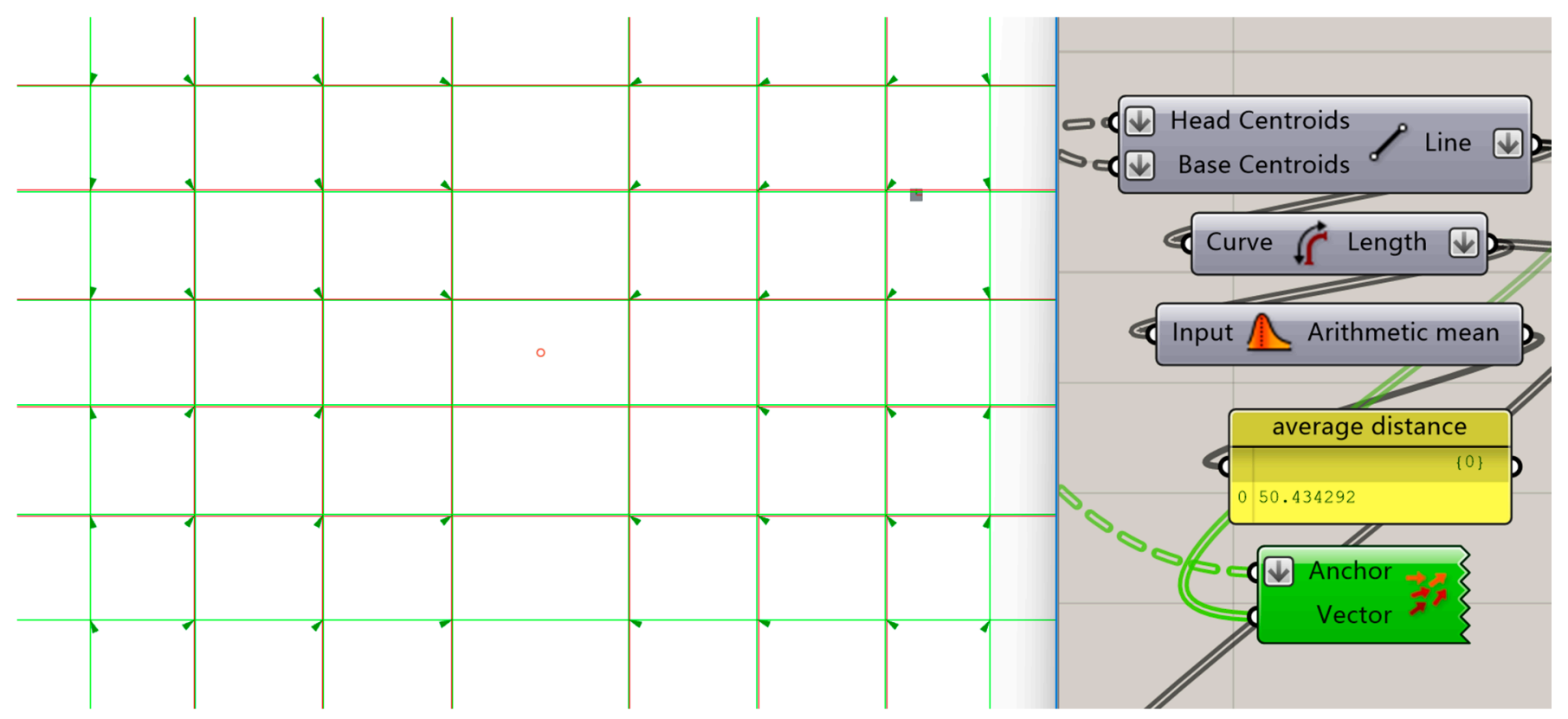

Figure 19. The inclination and the average distance.

Figure 20. The column height.

If they are designed to be inclined, the outer eaves columns are inclined inward in the front and back eaves, with $10 \%$ of the column height; $8 \%$ of the column height in the two sides eaves, and the corner columns are inclined in both directions at the same time.

After the manual check, the result shows that the inclination of the columns almost conforms to a designed inclination, as the average distance is $50 \mathrm{~mm}$, the column height is $5027 \mathrm{~mm}$, and the ratio is almost $10 \%$. However, this result still needs further investigation to confirm, as all of the columns have inclinations, rather than just eaves columns. This practice has not been found in historical archives or architectural books. The cause of this special inclination needs further research to verify whether this construction method of column inclination is common in other Imperial-style architectures.

Author Contributions: Conceptualization, X.W., C.W. and C.B.; Funding acquisition, C.W.; Investigation, X.W. and C.W.; Methodology, X.W., C.W. and C.B.; Project administration, C.W.; Resources, C.W.; Software, X.W.; Validation, X.W.; Visualization, X.W.; Writing-original draft preparation, X.W.; Writing-review and editing, X.W. and C.W. All authors have read and agreed to the published version of the manuscript.

Funding: This research was funded by Ministry of Science and Technology of the People's Republic of China (project No. 2020YFC1522400, No. 2020YFC1522405).

Institutional Review Board Statement: Not applicable.

Informed Consent Statement: Not applicable.

Data Availability Statement: The source code of the node-visible algorithm is not openly available due to the consideration of data safety. 
Acknowledgments: This paper was partially supported by the following institutions: The Qufu Administrative Bureau of Historical Relics, Qufu; The Qufu San Kong Heritage Architecture Engineering Management Office, Qufu; The Palace Museum, Beijing; Jiayuguan Academy of Silk Road (the Great Wall) Culture, Jiayuguan; Cultural Heritage Administration of Jizhou District, Tianjin.

Conflicts of Interest: The authors declare no conflict of interest.

\section{References}

1. Massafra, A.; Prati, D.; Predari, G.; Gulli, R. Wooden Truss Analysis, Preservation Strategies, and Digital Documentation through Parametric 3D Modeling and HBIM Workflow. Sustainability 2020, 12, 4975. [CrossRef]

2. Ba, Z.; Jiao, P.; Zhang, L.; Liu, B.; Zhang, X. Damaged Deformation Status and Seismic Performance Analysis of Guanghua Building in Jiayuguan. Technol. Earthq. Disaster Prev. 2020, 15, 293-304.

3. Yang, H.W.; An, D.W. Column-leaning Displacement of Korean Traditional Wooden Architecture: 3D Scanning Data of Columns of Sungryeoljeon in Namhansanseong. J. Asian Archit. Build. Eng. 2017, 16, 279-286. [CrossRef]

4. Xu, M.G.; Ding, Z.W. Study of Ultimate Displacement of Timber Structures in Chinese Ancient Buildings. In Proceedings of the 4th International Conference on Civil Engineering, Architecture and Building Materials (CEABM), Haikou, China, 24-25 May 2014; pp. 1759-1762.

5. Qiao, X. On the Form of Gongxian and Liaoli in Yingzao Fashi. Stud. Hist. Nat. Sci. 2007, 26, 523-536.

6. Park, Z. A Design of the Bracketing Set of Japanease Zen style seen from the viewpoint of an Immanent Oblique Line. J. Archit. Inst. Korea Plan. Des. 2002, 18, 101-108.

7. Chang, H. The Study of the Techniques of the Xia-ang Structure in China during the Tang and Song Dynasty. J. Archit. Hist. 2011, 20, 115-130.

8. Guo, Q. Yingzao Fashi: Twelfth-Century Chinese Building Manual. Archit. Hist. 1998, 41, 1-13. [CrossRef]

9. Wang, X.; Wu, C.; Que, R.; Bai, C. Algorithm Modeling of Ancient Architecture for Heritage Documentation. ISPRS-Int. Arch. Photogramm. Remote Sens. Spat. Inf. Sci. 2019, XLII-2-W15, 1209-1213. [CrossRef]

10. Wang, X.; Wu, C.; Que, R. Regularized Rebuild Workflow of HBIM for Built Heritage Documentation. ISPRS Ann. Photogramm. Remote Sens. Spat. Inf. Sci. 2021, VIII-M-1-2021, 193-200. [CrossRef]

11. Yang, J.; Wang, X.; Wu, C.; Bai, C. Regularized Reconstruction of Grid System for Traditional Chinese Timber Structure Building in Hbim. ISPRS—Int. Arch. Photogramm. Remote Sens. Spat. Inf. Sci. 2019, XLII-2/W15, 1229-1233. [CrossRef]

12. Soto-Martin, O.; Fuentes-Porto, A.; Martin-Gutierrez, J. A Digital Reconstruction of a Historical Building and Virtual Reintegration of Mural Paintings to Create an Interactive and Immersive Experience in Virtual Reality. Appl. Sci. 2020, 10, 597. [CrossRef]

13. Franco, P.A.C.; Rueda Márquez De La Plata, A.; Cruz Franco, J. From the Point Cloud to BIM Methodology for the Ideal Reconstruction of a Lost Bastion of the Cáceres Wall. Appl. Sci. 2020, 10, 6609. [CrossRef]

14. Li, D.; Wang, X.; Bai, C.; Wu, C. Discussion on the Problem of Regularized Reconstruction in Hbim. ISPRS-Int. Arch. Photogramm. Remote Sens. Spat. Inf. Sci. 2019, XLII-2/W15, 657-662. [CrossRef]

15. Wu, C.; Li, K.; Li, S.; Zhang, L. From digitization to informatization: The application of information technology in the field of Architectural Heritage. China Cult. Herit. 2016, 2, 18-24.

16. Murphy, M.; McGovern, E.; Pavia, S. Historic Building Information Modelling-Adding intelligence to laser and image based surveys of European classical architecture. ISPRS J. Photogramm. Remote Sens. 2013, 76, 89-102. [CrossRef]

17. Murphy, M.; McGovern, E.; Pavía, S. Parametric Vector Modelling of Laser and Image Surveys of 17th Century Classical Architecture in Dublin. In Proceedings of the 8th International Symposium on Virtual Reality, Archaeology and Cultural Heritage VAST, Brighton, UK, 26-30 November 2007.

18. Murphy, M.; McGovern, E.; Pavia, S. Historic building information modelling (HBIM). Struct. Surv. 2009, 27, 311-327. [CrossRef]

19. Martina, A. Informative Models for Architectural Heritage. Heritage 2019, 2, 2067-2089.

20. Capone, M.; Lanzara, E. SCAN-TO-BIM vs. 3D Ideal Model Hbim: Parametric Tools to Study Domes Geometry. ISPRS-Int. Arch. Photogramm. Remote Sens. Spat. Inf. Sci. 2019, XLII-2/W9, 219-226. [CrossRef]

21. Han, S.; Wu, C.; Li, D.; Li, J.; Liu, Y.; Feng, K.; Di, Y. Workflows for Condition Inspection Documentation Ofarchitectural Heritage Based on HBIM: Taking Three Duty Rooms Inforbidden City of Beijing as an Example. ISPRS-Int. Ann. Photogramm. Remote Sens. Spat. Inf. Sci. 2017, 4, 123. [CrossRef]

22. Collao, J.; Lozano-Galant, F.; Lozano-Galant, J.A.; Turmo, J. BIM Visual Programming Tools Applications in Infrastructure Projects: A State-of-the-Art Review. Appl. Sci. 2021, 11, 8343. [CrossRef]

23. Gigliarelli, E.; Calcerano, F.; Cessari, L. Heritage Bim, Numerical Simulation and Decision Support Systems: An Integrated Approach for Historical Buildings Retrofit. Energy Procedia 2017, 133, 135-144. [CrossRef]

24. Diara, F.; Rinaudo, F. Building Archaeology Documentation and Analysis through Open Source HBIM Solutions via Nurbs Modelling. ISPRS - Int. Arch. Photogramm. Remote Sens. Spat. Inf. Sci. 2020, 43, 1381-1388. [CrossRef]

25. Diara, F.; Rinaudo, F. From Reality to Parametric Models of Cultural Heritage Assets for HBIM. ISPRS-Int. Arch. Photogramm. Remote Sens. Spat. Inf. Sci. 2019, XLII-2/W15, 413-419. [CrossRef]

26. Bagnolo, V.; Argiolas, R.; Cuccu, A. HBIM for Archaeological Sites: From SFM Based Survey to Algorithmic Modeling. ISPRS-Int. Arch. Photogramm. Remote Sens. Spat. Inf. Sci. 2019, XLII-2/W9, 57-63. [CrossRef] 
27. Bagnolo, V.; Argiolas, R.; Cuccu, A. Digital Survey and Algorithmic Modeling in HBIM. Towards a Library of Complex Construction Elements. ISPRS-Int. Arch. Photogramm. Remote Sens. Spat. Inf. Sci. 2019, XLII-4/W12, 25-31. [CrossRef]

28. Argiolas, R.; Cazzani, A.; Reccia, E.; Bagnolo, V. From Lidar Data towards HBIM for Structural Evaluation. ISPRS-Int. Arch Photogramm. Remote Sens. Spat. Inf. Sci. 2019, XLII-2/W15, 125-132. [CrossRef]

29. Cubukcuoglu, C.; Ekici, B.; Tasgetiren, M.F.; Sariyildiz, S. Optimus: Self-Adaptive Differential Evolution with Ensemble of Mutation Strategies for Grasshopper Algorithmic Modeling. Algorithms 2019, 12, 141. [CrossRef]

30. Chen, X.; Wang, X. Parameterization of Yingzao Fashi: Generating the Palace Style Structural Carpentry System Based on Algorithmic Language. Huazhong Archit. 2016, 34, 41-43.

31. Brumana, R.; Della Torre, S.; Previtali, M.; Barazzetti, L.; Cantini, L.; Oreni, D.; Banfi, F. Generative HBIM modelling to embody complexity (LOD, LOG, LOA, LOI): Surveying, preservation, site intervention-The Basilica di Collemaggio (L'Aquila). Appl. Geomat. 2018, 10, 545-567. [CrossRef]

32. Wang, J.; He, J.X.; Yang, Q.S. Finite Element Analysis on Mechanical Behavior of Column Foot Joint in Traditional Chinese Timber Structures. In Proceedings of the 14th International Symposium on Structural Engineering (ISSE-14), Beijing, China, 12-15 October 2016; pp. 1396-1402.

33. Abbate, E.; Invernizzi, S.; Spanò, A. HBIM parametric modelling from clouds to perform structural analyses based on finite elements: A case study on a parabolic concrete vault. Appl. Geomat. 2020. [CrossRef]

34. Pepe, M.; Costantino, D.; Garofalo, A.R. An Efficient Pipeline to Obtain 3D Model for HBIM and Structural Analysis Purposes from 3D Point Clouds. Appl. Sci. 2020, 10, 1235. [CrossRef]

35. Brumana, R.; Banfi, F.; Cantini, L.; Previtali, M.; Torre, S.D. HBIM Level of Detail-Geometry-Accuracy and Survey Analysis for Architectural Preservation. ISPRS-Int. Arch. Photogramm. Remote Sens. Spat. Inf. Sci. 2019, XLII-2/W11, 293-299. [CrossRef]

36. Angjeliu, G.; Cardani, G.; Coronelli, D. Digital Modelling and Analysis of Masonry Vaults. ISPRS-Int. Arch. Photogramm. Remote Sens. Spat. Inf. Sci. 2019, XLII-2-W11, 83-89. [CrossRef]

37. Rutten, D. Galapagos: On the Logic and Limitations of Generic Solvers. Archit. Des. 2013, 83, 132-135. [CrossRef]

38. Vighnesh, R.; Anand, K.B.; Aadhish, B.K.; Divakar, S.; Kumar, C.M. Use of parametric tools in material system selection to minimize building cooling load. In Proceedings of the 2nd International Conference on Aspects of Materials Science and Engineering (ICAMSE), Chandigarh, India, 5-6 March 2021; pp. 4451-4457.

39. González, J.; Fiorito, F. Daylight Design of Office Buildings: Optimisation of External Solar Shadings by Using Combined Simulation Methods. Buildings 2015, 5, 560-580. [CrossRef]

40. Nadiri, P.; Mahdavinejad, M.; Pilechiha, P. Optimization of Building Facade to Control Daylight Excessiveness and View to Outside. J. Appl. Eng. Sci. 2019, 9, 161-168. [CrossRef]

41. Girotti, C.; Marins, K.R.d.C.; Lara, A.H. Análise da morfologia urbana para maximização de geração de energia fotovoltaica no Belenzinho, em São Paulo. Ambiente Construído 2019, 19, 7-22. [CrossRef]

42. Li, J.; Huang, Y.; Zhang, L.; Zhang, M. Climate Adaptability Optimization of Large Space Building form in Cold Area: Take Liaodong Bay Cruise Terminal Passenger Transport Center as an Example. Ind. Constr. 2021, 51, 6-11.

43. Vlaun, N.; van Waart, A.; Tenpierik, M.; Turrin, M. A Sound Working Environment: Optimizing the Acoustic Properties of Open Plan Workspaces Using Parametric Models. In Proceedings of the 7th Annual Symposium on Simulation for Architecture and Urban Design (SimAUD), London, UK, 16-18 May 2016; pp. 239-246.

44. Manni, M.; Lobaccaro, G.; Lolli, N.; Bohne, R.A. Parametric Design to Maximize Solar Irradiation and Minimize the Embodied GHG Emissions for a ZEB in Nordic and Mediterranean Climate Zones. Energies 2020, 13, 4981. [CrossRef]

45. Lobaccaro, G.; Wiberg, A.H.; Ceci, G.; Manni, M.; Lolli, N.; Berardi, U. Parametric design to minimize the embodied GHG emissions in a ZEB. Energy Build. 2018, 167, 106-123. [CrossRef]

46. Lee, S.; Lee, K.S. Optimization of Apartment-Complex Layout Planning for Daylight Accessibility in a High-Density City with a Temperate Climate. Energies 2020, 13, 4172. [CrossRef] 